\title{
Motivating Generation Y and Virtual Teams
}

\author{
Arthur M. Baldonado \\ Department of Business, Ashford University, Clinton, USA \\ Email: abaldo1212@hotmail.com
}

Received April 24, 2013; revised June 1, 2013; accepted June 8, 2013

Copyright (C 2013 Arthur M. Baldonado. This is an open access article distributed under the Creative Commons Attribution License, which permits unrestricted use, distribution, and reproduction in any medium, provided the original work is properly cited.

\begin{abstract}
How can team members remain effective if members cannot engage in face-to-face interactions? Although the concept of global virtual teams has been a relatively new phenomenon, their use by organizations is a growing trend. The growth of globalization and the explosion of new technology have led to a new paradigm-a workplace that has no walls or boundaries. The purpose of the qualitative, descriptive study was to explore the motivational needs of Gen Y virtual team members and their impact in the workplace based on Herzberg's two-factor theory of motivation. The participants consisted of Gen Y members at the Lakeland, Florida. The author used a researcher-developed, written survey as research methodology. The findings of the study revealed that Gen Y cohort placed great importance to both hygiene and motivator factors in their motivational needs. Advancement and personal life were both important to Gen Y participants. Managers must be flexible in their managerial approach to Gen Y workers.
\end{abstract}

Keywords: Generation Y; Virtual Team; Motivation

\section{Introduction}

How can team members remain effective if members cannot engage in face-to-face interactions? Such would be the case for a virtual project team in which the team members are geographically situated so that they may seldom, if ever, meet face-to-face as a team. Most organizations today are trying to find new and innovative ways to be more competitive and efficient. This paper will explore ways to manage virtual project teams which include defining virtual project team, providing literature review, and discussing advantages and disadvantages of project teams.

Millennials, Echo Boomers, Generation Y (Gen Y), and Nexters are some of the descriptors used to identify and label the newest generational cohort entering the workforce [1]. Referred to as Gen Y in the study, Gen Y workers have become a stronger and larger group in the workplace with more than 29 million members entering the workforce in the last seven years [2]. By aligning Gen Y employees' personal needs to corporate needs, managers and leaders will be able to attract and retain Gen Y workers while developing flexible and varied managerial behaviors [3]. Reference [4] noted that the needs of Gen Y workers appeared to be different than preceding generations in many ways: Gen $\mathrm{Y}$ are more numerous, in numbers, than Baby Boomers, perceived as more ambitious than the so-called Generation Xers, and more technology-knowledge than any of their predecessors.

\section{Background}

As Gen Y employees continue to become a stronger and larger group in the workplace, managers and executives must develop flexible and varied managerial behaviors to effectively motivate and manage this cohort. Thus, conducting research on generational differences, similarities, and needs are essential if managers are going to be equipped "with the knowledge required to make informed decisions and implement strategies for creating environments that people want to become part of and stay in" [5]. Failure to address generational issues may cause misunderstandings and miscommunications [6].

Bridging the generation gap between cohorts is vital if organizations are to thrive in the future. The majority of leaders in organizations overlook generational diversity. Sixty-six percent of leaders within organizations surveyed by the Equal Opportunity Employment Commission (EOEC) indicated that they had no age profile information in their workplace while eighty-one percent of leaders within those organizations failed to include crossgenerational issues in their diversity training. Nevertheless, understanding generational diversity will improve 
the competitive edge of an organization, increase recruitment, and retention, and ultimately create a stronger organization. Conversely, intergenerational conflict can have a catastrophic impact on morale and productivity, and it has the potential to lead to EEO complaints and lawsuits.

Findings from the qualitative descriptive research study are expected to add to the growing body of Gen Y research in effectively motivating and managing the newest entrants to the workforce. The qualitative descriptive study would also provide a study upon which others can build, such as using a quantitative approach to study the relationship between motivational factors affecting Gen Y and Gen X. Becoming familiar with and understanding the emerging workforce should be a priority for both researchers and practitioners. In agreement, Reference [7] wrote that younger employees might be motivated and challenged in ways different from earlier generations. The qualitative descriptive study will attempt to understand the motivational needs of Gen Y workers.

\section{Virtual Teams}

Reference [8] defined virtual project team as "spatially separated project team whose members are unable to communicate face to face. Communication is usually by electronic means” (p. 650). Virtual teamwork is regarded as an important form of work in modern organizations as it is capable of complying with the demands of the new business environments characterized by global competition, demanding markets, and rapidly changing technologies [9].

Reference [10] listed seven types of virtual teams.

1) Network-Team membership is diffuse and fluid; members come and go as needed. Team lacks clear boundaries within the organization.

2) Parallel-Team has clear boundaries and distinct membership. Team works in the sort term to develop recommendation for an improvement in a process or system.

3) Project or product development-Team has fluid membership, clear boundaries, and a defined customer base, technical requirement, and output. Longer-term team task is no routine, and the team has a decisionmaking authority.

4) Work or production-Team as distinct membership and clear boundaries. Members perform regular and outgoing work, usually in one functional area.

5) Service-Team has distinct membership and supports ongoing customer network activity.

6) Management-Team has distinct membership and works on a regular basis to lead corporate activities.

7) Action-Team deals with immediate action, usually in an emergency situation. Membership may be fluid or distinct [10].
The historical origination of generational theory has been around for centuries and many citing the writers of the Old Testament as the originators of the generational discussion [11]. Reference [12] noted that "the very term birth cohort was not coined until 1863 (by the French sociologist Emile Littre), and the concept attracted little attention over the next hundred years [12]. Howe and Strauss provided a seminal foundation and comprehensive explanation of American generations. Thus, Howe and Strauss defined generation as:

A special cohort-group whose length approximately matches that of a basic phase of life, or about twentyyear over the past three decades (p. 34) and as a cohortgroup whose length approximates the span of a phase of life and whose boundaries are fixed by peer personality [12].

Reference [12] emphasized that a generational cohort consists of individuals who share a given life experience, is historically or socially structured, and has a common generational framework. Additionally, [13] defined a generation as an identifiable age group with a shared historical experience. Eras and social movements, such as the Civil Rights era or the women's movement, provide distinct experiences for individuals who live during the same years [13].

Reference [13] noted the historical cyclical approach developed by Arthur Schlesinger, an American historian. Howe and Strauss expanded Schlesinger's work by hypothesizing that generations can be understood and viewed by four cycles; the cycles usually span the length of a human life, about 80 years or 20 years per cycle. Thus, Howe and Strauss concluded that over an 80-year span, generations go through four 20-year stages. The term new turning is the foundation of the cyclical approach, where every four cycles a major upheaval in the society takes place. The authors explained these new turnings usually catch a society by surprise and cited examples of new turning events in history such as the 1770 colonists surprise revolution and the 1929 Great Depression. Finally, Howe and Strauss further hypothesized that the American culture is currently experiencing a new turning, and Generation $\mathrm{Y}$ will be at the helm of the changes associated with this new turning.

\subsection{Two-Factor Theory}

Reference [14] developed the motivator/hygiene theory or two-factor theory. Herzberg began his research in the mid-1950s by surveying 200 engineers and accountants for framework around their motivators [15]. By combining his findings with other researchers using different frameworks, Herzberg developed a model of motivation on the assumption that factors eliciting job satisfaction and motivation are independent from those producing job 
dissatisfaction.

The two-factor theory assumes that factors producing job satisfaction (motivators, or intrinsic rewards) differ from those producing job dissatisfaction (hygiene factors, or extrinsic rewards). The motivators are "achievement, recognition for achievement, the work itself, responsibility, and growth or advancement" [14]. The hygiene or dissatisfaction-avoidance factors, which are extrinsic to the job, include "company policy and administration, supervision, interpersonal relationships, working conditions, salary, status, and security" [14].

Herzberg concluded that removing hygiene factors did not guarantee employee satisfaction, but simply brought peace within an organization and does not motivate employees. Satisfaction is only increased with motivators, suggesting job roles should be redefined to increase recognition, responsibility, achievement, and advancement.

\subsection{Statement of the Problem and Purpose}

There is little scholarly research on Gen Y members entering the workforce and little is known about their employment needs. Extensive searching for previous doctoral level research on motivation and related ventures has yielded only two studies for Gen Y. Dulin analyzed motivation and leadership preferences of a Gen Y cohort while the Reference [16] examined training linearity and motivation across generations. Similarly, previous doctoral level research across generations on motivation produced several studies; however, a review of the dissertation literature produced two notable studies [17]. Janiszewsk and Koenigsknecht explored the motivational factors influencing the Baby Boomers and Generation X generations.

\section{Statement of Research Questions}

The following research questions were used to guide the qualitative descriptive study of Generation Y workplace motivational factors based on Frederick Herzberg's two-factor theory model with Generation Y at the Lakeland DEP Recruiting station:

1) What motivator factors help motivate Gen Y employees in the workplace?

2) What hygiene factors help motivate Gen $Y$ employees in the workplace?

3) What strategies can managers provide to strengthen job satisfaction of Gen Y employees?

\subsection{Methodology}

This researcher explored and described the motivational and management needs of Gen Y members and has selected a qualitative, descriptive research approach to collect the primary data. This study is qualitative and descriptive in nature, as it does not assess causal relation- ship, but instead, compiles and describes data. Descriptive studies can provide a one-time snapshot or description of a population or a phenomenon at a given point in time [18].

The data was gathered using a researcher-designed, written questionnaire and was administered to Lakeland US Air Force Delayed Entry Program (DEP) Recruits. The researcher-designed, written questionnaire was examined by three college professors at Northcentral University for validity and reliability. Additionally, a pilot study was conducted and administered to Gen Y personnel at Hickam Air Force Base for soundness of survey instrument. The survey composed of two sections: 1) Demographic sections; and 2) Two-factor theory questionnaire

The results of the study are intended to provide a body of knowledge relating to the motivational and management needs of Gen Y. The need for this study is significant and useful for management in helping analyze the motivational and management needs of Gen Y.

\subsection{Survey Results}

Section A responses to demographic information indicate majority of the respondents were male and none of respondents listed their academic level. The study successfully targeted Gen Y members-all of the survey participants were Gen Y members (born after 1980). The ethnicity of the majority of survey respondents was Caucasian.

In Section B, the researcher sought to explore the importance of the 16-hygiene/motivator factors of Herzberg's two-factor theory of motivation (1968). Ten hygiene factors were surveyed in this study: security, status, relationship with subordinates, personal life, and relationship with peers, salary, work conditions, relationship with supervisor, supervision, and company policy/administration. Since hygiene factors are extrinsic to the individual, their absence caused dissatisfaction. However, hygiene factors do not lead to higher levels of motivation (Herzberg, 1968).

The survey responses indicated Gen Y strongly agreed on the importance of balancing personal life with one's professional life (58.62\% of respondents). Reference [18] noted that one of the overwhelming values of Gen Y workers was their shared norm of "work to live" ideology. As this generation search for jobs, Eisner observed that Gen Y had different priorities. For instance, Gen Y members watched in horror as their parents worked punishing hours in their quest for status and money [19]. Gen Y members cared less about salaries and cared more about flexible working hours, time to travel, and a better worklife balance [20]. Below depicts the survey's answer to the hygiene factor of personal life. 


\begin{tabular}{cc}
\hline \multicolumn{2}{c}{ Hygiene Factor of Personal Life } \\
\hline \multicolumn{2}{c}{ as my professional life. } \\
Personal life-My personal life is just as important \\
Very Important & $58.62 \%$ \\
Important & $27.58 \%$ \\
Moderately Important & $10.34 \%$ \\
A Little Important & $3.44 \%$ \\
Not Important & 0 \\
& $(\mathrm{~N}=29)$ \\
& $($ Mean $=1.5)$ \\
\hline
\end{tabular}

Other hygiene factors that received high ratings from Gen Y include job security and relationship with subordinates and peers, salary, work conditions, and company policy/adminatriton. Likewise, survey responses that showed moderate importance were status, relationship with supervisor, and supervision. Thus, survey responses indicated majority of Gen Y participants placed high preferences on having a good work-life balance, job secruity, and relationships with subordinates and peers.

Six motivator factors were surveyed in the study: achievement, recognition, work itself, responsibility, advancement, and growth. Herzberg stated that motivator factors, if present, led to feelings of satisfaction and were needed to motivate employees into higher performance because motivator factors result from intrinsic instincts in workers, yielding motivation [21].

Survey responses depicted advancement, growth, responsibility, achievement, and work itself as high motivators to Gen Y participants. Similarly, recognition was viewed as important to survey respondents. Reference [20] validated this finding by stating the most important strategy companies can do for Gen Y was to meet their advancement, growth, and personal needs by motivating their intrinsic needs. Below depicts the survey's answer to the motivator factor of growth.

\begin{tabular}{cc}
\hline \multicolumn{2}{c}{ Motivator Factor of Advancement } \\
\hline Advancement—Advancing in my career is important to me. \\
Very Important & $79.31 \%$ \\
Important & $17.24 \%$ \\
Moderately Important & $3.44 \%$ \\
A Little Important & 0 \\
Not Important & 0 \\
& $(\mathrm{~N}=29)$ \\
& $($ Mean $=1.2)$ \\
\hline
\end{tabular}

The 16 hygiene/motivator factors received a mean ranging from 1.2 to 2.5 (with an average mean of 1.7). The results of the survey indicated that Gen Y participants regard both hygiene and motivator factors as important to their motivational needs. However, two hygiene-motivator factors emerged as the top motivators of Gen Y -advancement and personal life. Below ranks the frequency of importance of the survey's Hygiene-Motivator factors, based on mean value.

\begin{tabular}{cc}
\hline \multicolumn{2}{c}{ Hygiene/Motivator Factors Rank of Importance } \\
\hline Hygiene Factors & Motivator Factors \\
Personal life $(\mathrm{M}=1.5)$ & Advancement $(\mathrm{M}=1.2)$ \\
Working conditions $(\mathrm{M}=1.6)$ & Growth $(\mathrm{M}=1.3)$ \\
Relationship with subordinate $(\mathrm{M}=1.6)$ & Responsibility $(\mathrm{M}=1.4)$ \\
Security $(\mathrm{M}=1.6)$ & Achievement $(\mathrm{M}=1.4)$ \\
Relationship with peers ( $\mathrm{M}=1.8)$ & Work itself $(\mathrm{M}=1.5)$ \\
Salary (M = 1.8) & Recognition $(\mathrm{M}=2)$ \\
Relationship with supervisor $(\mathrm{M}=2)$ \\
Relationship with supervisor $(\mathrm{M}=2)$ \\
Company policy/admin ( $\mathrm{M}=1.8)$ \\
Supervision ( $\mathrm{M}=2.2)$ \\
Status ( $\mathrm{M}=2.5)$
\end{tabular}

\subsection{Discussion/Recommendation}

Unlike traditional team, a virtual team works across space, time, and organizational boundaries with links strengthened by webs of communication technologies [20]. A survey of firms identified that almost three fifths are suing global virtual teams to undertake a variety to tasks [22].

Reference [22] noted that many of the elements that constitute successful face-to-face teams are also necessary for successful virtual teams. The key factors of success include high level of trust, clear communication, strong leadership, and appropriate levels of technology.

To the author's knowledge, this study is one of the only few to directly address Gen Y motivational needs utilizing Frederick Herzberg's two-factor theory of motivation. Gen Y workers present the next colossal opportunity and the next significant challenge for managers and business leaders in the new economy. As Gen Y continues to grow and enter the workforce, the need to effectively manage Gen Y employees become paramount for managers and business leaders. This study should help managers and leaders in identifying the motivational and managerial needs of Gen Y workers and should add to the growing body of knowledge on effectively managing 
and motivating Gen Y workers and virtual teams.

Perhaps the greatest benefit of this study is that it will increase awareness and discussion among managers and business leaders on how to effectively motivate and manage Gen Y members in the workplace. While other theories of motivation may prove useful in exploring workplace motivational and managerial factors of Gen Y workers, this researcher was intrigued in the popularity and utility of the two-factor theory among business practitioners.

It is recommended that managers and leaders tailor their managerial needs to effectively and better motivate/ manage Gen Y members. Having a flexible, adaptable approach can help managers better understand and motivate this emerging cohort. Next, managers must understand the basic trait of Gen Y-independent, collaborative, techno-savvy, and multitasking workers. Gen Y members want meaningful/challenging work that let them grow on their jobs. Likewise, Gen Y workers value the importance of balancing their personal and professional lives. Leaders and managers who understand Gen Y needs of growth and work/life balance will gain the competitive edge of an organization, increase recruitment and retention, and ultimately create a stronger organization.

\section{Limitation of Study/Future Research}

Areas requiring further research include: 1) measuring the difference (if any) in hygiene/motivator factors among Gen Y workers; 2) determining if results from a replicated study using respondents who are actually employed agree or disagree with the finding of this study; 3) how motivator and hygiene factors impact Gen Y employees in the workplace.

The data from the present study depicts Gen Y members value both hygiene and motivator factors of Frederick Herzberg's two-factor theory of motivation. Personal life emerged as the top hygiene factors for Gen Y while advancement needs garnered the highest rating as a motivator factor. Effectively motivating Gen Y is one of a manager's top duties. Thus, there are many ways to motivate workers, and it is just a matter of finding the right factors that suit an individual.

\section{Conclusions}

The ability to manage and conduct business without walls or boundaries is a 21 st century paradigm that is gaining momentum [23]. Using global virtual teams to undertake projects without the shackles of geography, time, and physical location is enabling firms to conduct business in regions that were previously thought of as inaccessible. Virtual teams offer the promise of flexibility, responsiveness, lower costs and the improved resource utilization necessary to meet the ever changing task require- ments of firms operating in highly turbulent and dynamic global business environment. Finally, this researcher conclude that virtual team are here to stay and can be a competitive edge for organizations today.

Today's workforce is more diverse than ever. As Gen $\mathrm{Y}$ employees continue to become a stronger and larger group in the workplace, managers and executives must develop flexible and varied managerial behaviors to effectively motivate and manage this cohort [23]. The purpose of the qualitative descriptive study was to explore the motivational needs of Gen Y and their impact in the workplace based on Herzberg's two-factor theory model. The objective of this research is to provide managers with tools needed to manage Gen $\mathrm{Y}$ and to add to the growing body of knowledge in managing and motivating Gen Y.

\section{REFERENCES}

[1] L. Dulin, "Leadership Preferences of a Generation Y Cohort: A Mixed Method Investigation,” Doctoral Dissertation, University of North Texas, 2005.

[2] C. A. Martin and B. Tulgan, "Executive Summary: Managing the Generation Mix 2007,” 2007. www.rainmakerthinking.com/mix2007.doc

[3] S. P. Eisner, "Managing Generation Y," S.A.M Advanced Management Journal, Vol. 70, No. 4, 2005, pp. 4-15.

[4] C. L. Wall, "Generation Y? Because We Need You: The Relationships among Work-Related Values and Career Decision Self-Efficacy,” Doctoral Dissertation, Fielding Graduate Institute, 2004.

[5] M. Legault, "Bringing People Together: A Study of Generational Diversity and Organizational Culture,” Doctoral Dissertation, Royal Roads University, Canada, 2002.

[6] K. W. Smola and C. D. Sutton, "Generational Differences: Revisiting Generational Work Values for the New Millennium,” Journal of Organizational Behavior, Vol. 23, No. 4, 2002, pp. 363-382. doi:10.1002/job.147

[7] F. Kunreuther, "The Changing of the Guard: What Generational Differences Tell Us about Social-Change Organizations?” Nonprofit and Volunteer Sector Quarterly, Vol. 32, No. 3, 2003, pp. 450-457. doi:10.1177/0899764003254975

[8] E. W. Larson and C. F. Gray, "Project Management: The Managerial Process,” 11th Edition, McGraw-Hill Hills Companies, Inc., New York, 2011.

[9] L. J. Gressgard, "Virtual Team Collaboration and Innovation in Organizations," International Research Institute of Stavanger, Vol. 17, No. 1-2, 2011, pp. 102-119.

[10] H. Kerzner, "Project Management: A Systems Approach to Planning, Scheduling, and Controlling," 10th Edition, John Wiley \& Sons, Inc., Hoboken, 2009.

[11] C. J. Gonzalez, "A Causal Comparative Study of Work Ethic as a Function of Generational Cohorts,” Doctoral Dissertation, University of Phoenix, 2006.

[12] N. Howe and W. Strauss, "Generations: The History of 
America’s Future, 1584 to 2069,” William Morrow \& Co., New York, 1991.

[13] C. A. Martin and B. Tulgan, "Managing Generation Y: Global Citizens Born in the Late Seventies and Early Eighties,” HRD Press, Amherst, 2011.

[14] F. Herzberg, "One More Time: How Do You Motivate Employees?” Harvard Business Review, Vol. 81, No. 1, 1968, pp. 87-96.

[15] J. A. Wagner and J. R. Hollenbeck, "Organizational Behavior: Securing a Competitive Advantage,” Harcourt College Publishers, Forth Worth, 2001.

[16] S. E. Schlichtemeier-Nutzman, "Linearity across Generations: An Exploratory Study of Training Techniques," Doctoral Dissertation, The University of Nebraska, Lincoln, 2001.

[17] R. D. Janiszewski, "Motivational Factors That Influence Baby Boomers versus Generation X: Independent Insurance Agents,” Doctoral dissertation, Capella University, 2004.

[18] W. Trochim, “The Research Methods Knowledge Base,” 2nd Edition, Atomic Dog Publishing, Cincinnati, 2001.

[19] L. C. Lancaster and D. Stillman, "The Generational Gap at Work," The Worklife Report, Vol. 14, No. 4, 2003, p. 20.

[20] L. Lancaster and D. Stillman, "When Generations Collide: Who They Are. Why They Clash. How to Solve the Generational Puzzle at Work," Collins Business, New York, 2002.

[21] S. K. Koenigsknecht, "A Comparison of the Motivational Factors of Baby Boomer and Generation X Employees,” Doctoral Dissertation, Colorado Technical University, 2002.

[22] B. J. Bergiel, E. B. Bergiel and P. W. Balsmeier, "Nature of Virtual Teams: A Summary of Their Advantages and Disadvantages,” Management Research News, Vol. 31, No. 2, 2008, pp. 99-110.

[23] J. McLean, "Managing Global Virtual Teams," The British Journal of Administrative Management, Vol. 59, No. 2, 2007, pp. 16-17. 